\title{
Optimizing of Make Up Air Performance for Commercial Kitchen Ventilation Improvement
}

\author{
B. Manshoor ${ }^{1, \text { a }}$, I. Zaman ${ }^{1}$, N. Asmuin ${ }^{1}$, F. Ramlan ${ }^{1}$ and Amir Khalid ${ }^{1}$ \\ ${ }^{1}$ Centre for Energy and Industrial Environment Studies (CEIES) Faculty of Mechanical and \\ Manufacturing Engineering, Universiti Tun Hussein Onn Malaysia, 86400 Pt. Raja, Batu Pahat, Johor, \\ Malaysia
}

\begin{abstract}
A commercial kitchen is a complicated environment where multiple components of a ventilation system including kitchen hood, exhaust fan, air supply, and make up air systems work together but not always in unison. For the commercial kitchen environment, make up air systems used to control the kitchen space from unwanted odor and thermal confort. Make air systems for commercial kitchen already established. However, an optimization is important to determine the most suitable make air systems and at the same time can improve the thermal comfort in the working space. In this study, a simulation work was conducted to investigate a suitable supply air velocity to optimize the make up air for kitchen ventilation system. In order to achieve the objectives, ANSYS FLUENT software (CFD) was used to carry out the simulation and analysis. 3D kitchen space with $10 \mathrm{~m} \times 8 \mathrm{~m} \times 3 \mathrm{~m}$ with air supply velocity was set to $0 \mathrm{~m} / \mathrm{s}, 0.14 \mathrm{~m} / \mathrm{s}, 0.28 \mathrm{~m} / \mathrm{s}$ and $0.42 \mathrm{~m} / \mathrm{s}$. From the simulation work, the velocity of air flow tested which is $0.28 \mathrm{~m} / \mathrm{s}$ is enough to control the heat and give an enough comfort to the working space for the size of kitchen simulated. Well implementation of the make up air in the kitchen hood can improve an air quality in the commercial kitchen and also keep the kitchen space comfortable to the workers.
\end{abstract}

\section{Introduction}

A commercial kitchen exhaust hood must ensure complete capture and containment of the effluent produced by the cooking processes [1]. Cooking process in commercial kitchens create heat, gases, vapors, fumes and particles. Ventilation that controls these emissions is needed to reduce a variety of risks. Risks include fire from grease fumes deposited on surfaces [2]. The ventilation process has driven strategies to optimize appliance and hood configurations in an effort to reduce the energy required for the exhaust fan and for tempering the supply air [3]. The air quality is affected by high emission rate of contaminants released from the cooking process. Ventilation plays an important role in providing a comfortable and productive working condition and in contaminant removal. There has three factor affecting thermal comfort: air temperature, air velocity and air humidity [4]. This research is carried out to investigate the appropriate velocity of air supply for ventilation system in commercial kitchen.

Ventilation system in commercial kitchen is a very complex system. There were few factors that give an affect for ventilation system in kitchen area such as cooking factor itself, installation of kitchen hood, ventilated ceiling, and types of exhaust fan [5]. Based on the ASHRAE handbook on HVAV application for improving commercial kitchen ventilation system performance, it shows that the main factor in ventilation system is cooking factor. Cooking factors are categorized as light duty,

\footnotetext{
abukhari@uthm.edu.my
}

This is an Open Access article distributed under the terms of the Creative Commons Attribution License 2.0, which permits unrestricted use, distribution, and reproduction in any medium, provided the original work is properly cited. 
medium duty, heavy duty and extra heavy duty, depending on the strength of thermal plume, and the quantity of grease, smoke, gases, vapors, heat, and particles. The strength of thermal plume is a major factor in determine the exhaust rate [6].

ASHRAE handbook on HVAC application also mentioning that the hood factor is important in ventilation system for commercial kitchen. The design of exhaust rate depends on the hood style. They are several types of hood style; wall-mounted canopy hood, island canopy hood, double island canopy hood, and proximity (back shelf) canopy hood. For the proximity canopy hood, there are two types of design which are effective and ineffective design. Effective design is the hood of canopy which is larger than the heat source while the ineffective design of the hood canopy is smaller than heat source. Ineffective design caused the capture of emission are low and make the kitchen area in the zone of uncomfortable. For this study, proximity canopy with effective design are chosen for types of hood canopy because it can be applied with success at very low exhaust rates to capture and contain the cooking effluent.

Ventilated ceiling is an alternative kitchen exhaust system. The ceiling should be used for aesthetic reasons when open space is required. Ventilated ceilings are categorizedas "open" and "closed" ceiling system. Open ceiling is usually assembled from exhaust and supply cassettes. The contaminated air goes via the slot where grease and particles are separated. For the closed ceiling, supply and exhaust units are connected to the ductwork. There are also combinations of hoods and ventilated ceiling. Supply air delivered into the kitchen through the low velocity unit. Closed ventilated ceiling are used as the air supply for this study [7].

Others factor for ventilation system in commercial kitchen is make up air. Make up air is supplied through the displacement ventilation diffusers remote from the hood. There are three steps to reducing make up air. Firstly, minimize the design of exhaust rate. Next, outside air must be supplied by the HVAC system requirements for ventilating the kitchen area and finally select a local make up air into the kitchen complements $[5,8]$.

\section{Make Up Air}

Make up air is introduced to facilitate efficient capture and contain in kitchen hoods. There are several strategies includes: displacement ventilation/diffuser, air curtain diffuser, short-circuit supply, front face diffuser and perforated perimeter. Air curtain is the most of the hood manufactures recommend limiting the percentage of make-up air supplied through an air curtain less than $20 \%$ of the hood's exhaust flow. At such low air velocities, an air curtain may enhance capture and contain depending on design details [9]. Another strategy is known as displacement diffuser. Supplying make-up air through displacement diffuser is an effective strategy for introducing replacement air. Unfortunately, displacement diffusers require floor or wall space that is usually at a premium in the commercial kitchen. A possible solution may be remote displacement diffusers (built into a corner) to help distribute the introduction of makeup air into the kitchen when transfer air is not viable.

Short-circuit supply is also one of the strategies make-up air. It was internal make-up hoods were developed as a strategy to reduce the amount of conditioned air required by an exhaust system. The laboratory testing demonstrated that when short circuit hoods are operated with excessive internal make-up air, they fail to capture and contain the cooking fluent, often spilling at the back of the hood. On other hand, supplying air through the front face of the hood is a configuration recommended by many hood manufacturers. In theory, air exits the front face unit horizontal into the kitchen space. However, a front face discharge with louvers or perforated face can perform poorly, if it's designed perforated face supply, which negative affected this hood's capture performance in same fashion as an air curtain or four-way diffuser.

Perforated perimeter supplies are similar to a front face supply, but the air is directed downward. This may be advantageous under some condition, since the air is directed downward into the hood capture zone. One of the design of perforated perimeter known as four-way ceiling diffuser. Four-way ceiling diffuser located close to kitchen exhaust hood. Perforated plate ceiling diffusers can be used in the vicinity of the hood, and a greater number of ceiling diffuser reduces air velocities for given supply rate. 


\section{Research Objective and Model}

As mentioned above, the make up air is introduced to facilitate efficient capture and contain in kitchen hoods. Thus, the objective of this research is to investigate the requirement of air supply for optimizing the make up. To realize the objective, a simulation work had been conducted to determine the optimum air supply for make up in order to improve a commercial kitchen ventilation system performance.

The simulation work are based on 3 dimensional kitchen with a dimension of $10 \mathrm{~m} \times 8 \mathrm{~m} \times 3 \mathrm{~m}$ as showed in Fig. 1. For the supply air, three velocities were choose based on the most air supply used from available commercial air curtain in the market which are $0.05 \mathrm{~m} / \mathrm{s}, 0.15 \mathrm{~m} / \mathrm{s}$ and $0.25 \mathrm{~m} / \mathrm{s}$. Another model were simulated with $0 \mathrm{~m} / \mathrm{s}$ (without air supply) in order to determine the effect of the comfort level in the kitchen without the air supply for make up air. Kitchen hood is design in two different sizes but in the same type of canopy (proximity/back shelf). The location of kitchen hood is $2 \mathrm{~m}$ from the ground and $1.1 \mathrm{~m}$ from the heat source. Supplied air was design at the ceiling and it is

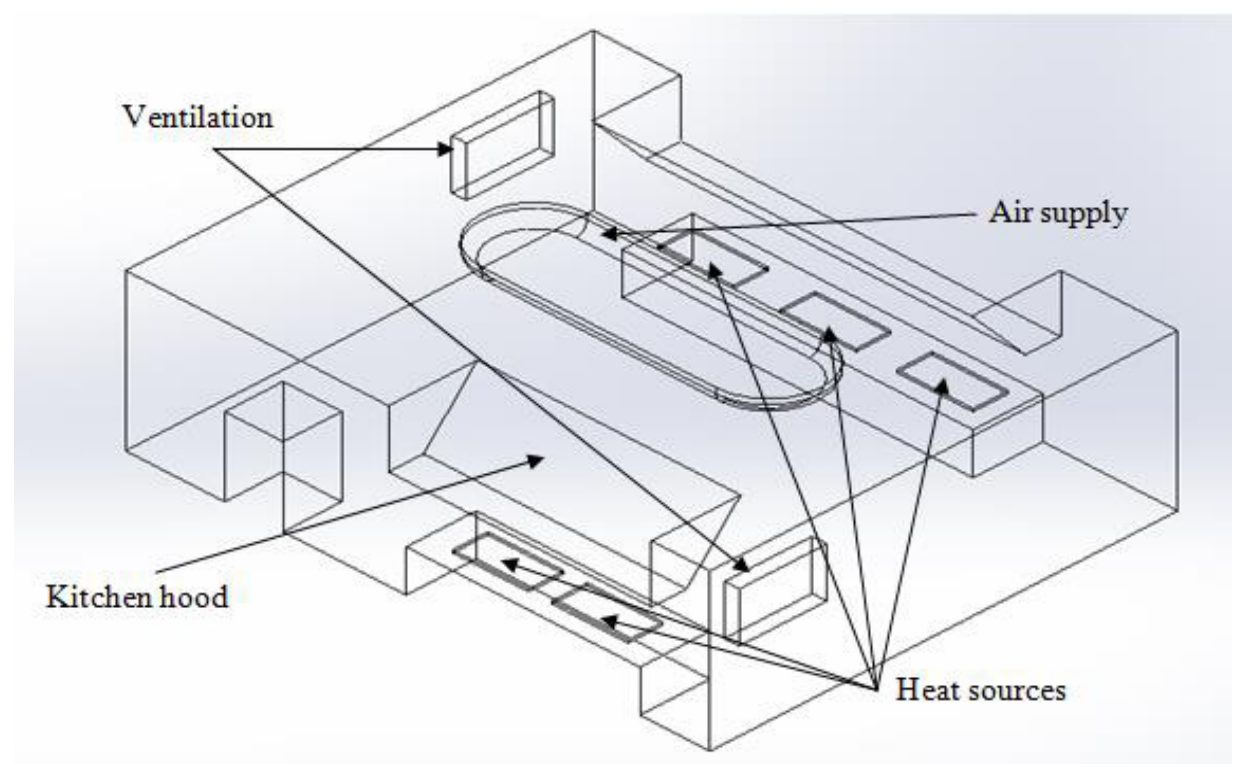

Fig. 1. Model of commercial kitchen simulated.

\section{Simulation Work}

The simulation work done by using commercial CFD software package ANSYS Fluent. An unstructured mesh was adopted for the spatial discretization of the domain, ensuring a better refinement in regions where higher gradients were expected. The turbulent at all boundaries condition has been set to $2 \%$ and back flow turbulent intensity at all boundaries has been set to $5 \%$. The SemiImplicit Method for Pressure Linked Equation (SIMPLE) method is used to reach a convergent solution set. For this research, kitchen hood was defined as outlet, supply air as inlet, ventilations as exhaust fan, heat source as heat source and the others was define as a wall. The standard $\mathrm{k}-\varepsilon$ model is the most common turbulence model and it is routinely used for indoor environment analysis [10]. It is also provide the easiest convergences in its formulation [6].

The boundary condition is the most important things in simulation. For this research, heat source was defined as velocity inlet with a $1273 \mathrm{~K}$ of temperature. Kitchen hood or outlet was defined as outlet-vent with the temperature $300 \mathrm{~K}, 120 \mathrm{~Pa}$ for pressure and $1.584 \mathrm{~kg} / \mathrm{s}$ for mass flow rate. Supply air was defined as velocity inlet with temperature $295 \mathrm{~K}$ and velocity at $0 \mathrm{~m} / \mathrm{s}, 0.14 \mathrm{~m} / \mathrm{s}, 0.28 \mathrm{~m} / \mathrm{s}$ and $0.42 \mathrm{~m} / \mathrm{s}$. Exhaust fan with the mass flow rate $0.6728 \mathrm{~kg} / \mathrm{s}$ and temperature $300 \mathrm{~K}$ define as ventilations. The kitchen wall also defines as the wall. 


\section{Results and Discussion}

The primary objective of this study is to determine the optimum air supply for kitchen ventilation. In order to discuss the results obtain from the simulation work, two types of results were come out which are the temperature and velocity distribution at certain place in the kitchen space. For this research purpose, place was chosen to examine the temperature and velocity distribution which are at $1.5 \mathrm{~m}$ from the floor. This location was chose because there are the critical places that need the comfort in the kitchen space. The plots of temperature and velocity distribution along the horizontal line at the location were shown in Fig. 2 and Fig. 3.

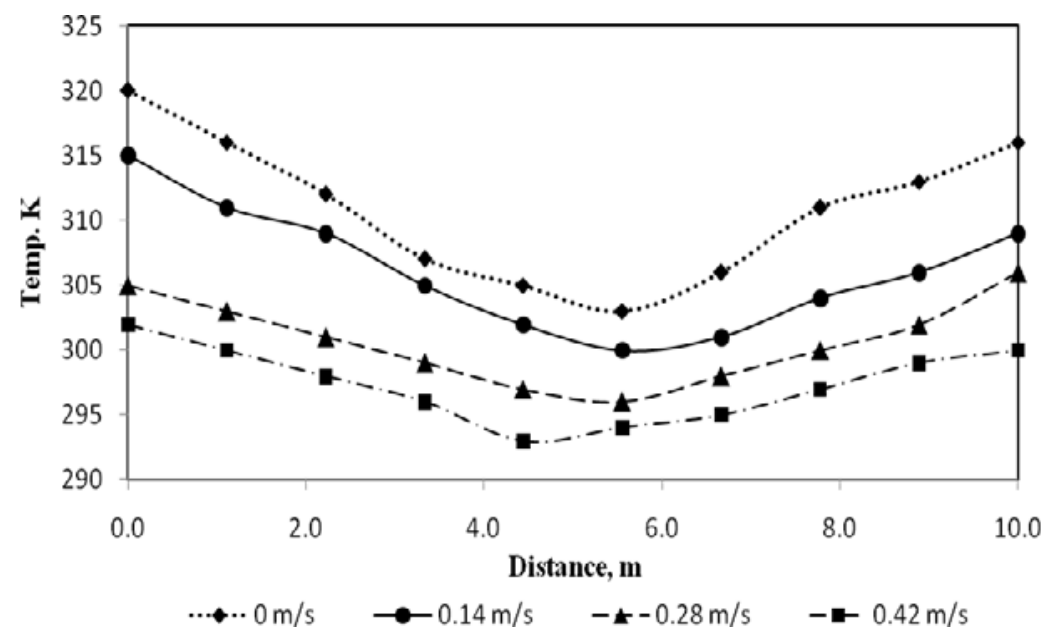

Fig 2. Temperature distribution along the horizontal line at $1.5 \mathrm{~m}$ from the floor

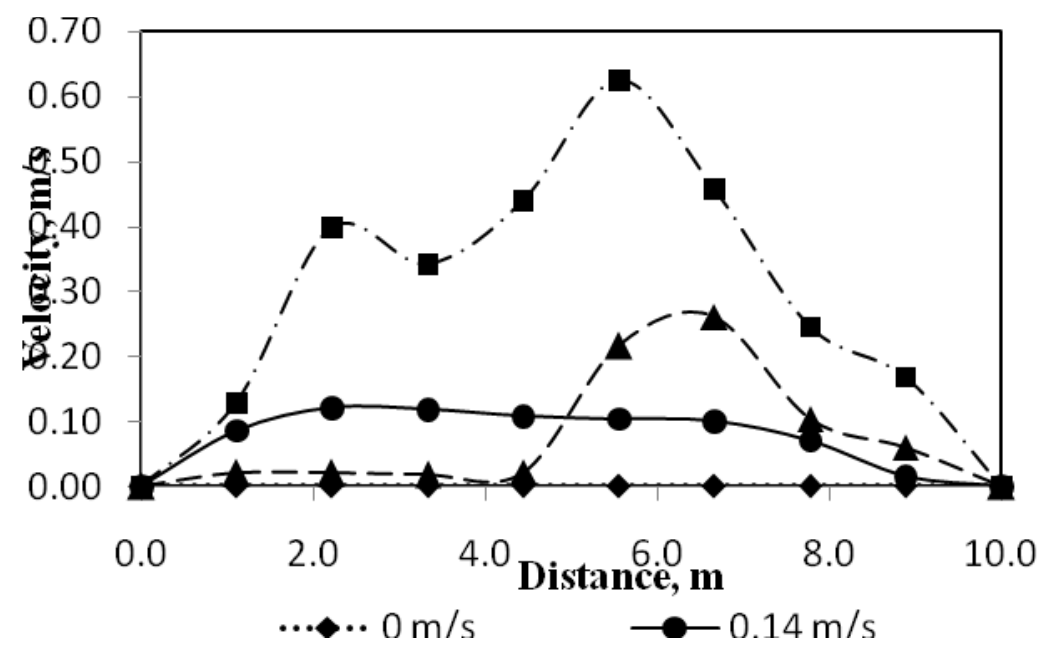

Fig 3. Velocity distribution along the horizontal line at $1.5 \mathrm{~m}$ from the floor

From the temperature and velocity distribution, it clearly showed that the increase of air supply for make up air will decrease the temperature distribution in the kitchen space especially at the centre of the kitchen (the place where the most workers are doing their job). However, for the optimum design for these study, the velocity of $0.28 \mathrm{~m} / \mathrm{s}$ are the most suitable air flow. This is because the high velocity of air supply simulated here showed that the temperature decrease to around $293 \mathrm{~K}$ which are not suitable for the kitchen space. Beside that, the high air supply need a high fan to blow the air, hence will increase the energy use for the system. Similar to the velocity, high velocity of the air 
supply will disturbed the main area of working place. As in commercial kitchen, controlling the temperature of cooking is important to make sure the food prepare by are in within the standard that they need.

\section{Conclusion}

In ventilation system, has a three main factors affecting thermal comfort; air velocity, air temperature and air humidity. This study investigated and analyzed the velocity and temperature at the commercial kitchen area. The air supply velocity is variable parameter for this study. Based on the results, the velocity for the air supply affecting the temperature at the kitchen area. Without supply air, the temperature was increasing and makes an area hot and uncomfortable for the user. At the highest velocity of supply air, $0.42 \mathrm{~m} / \mathrm{s}$, its help to decrease the temperature and make the kitchen area in comfortable zone. But at the same time, the highest of velocity are disturbing the area of heat source and make a difficult to do a work. For the velocity $0.14 \mathrm{~m} / \mathrm{s}$ of supply air have shown the kitchen area still in the uncomfortable zone. This is because for the velocity $0.14 \mathrm{~m} / \mathrm{s}$ at the supply air is not suitable using for the huge commercial kitchen hood. From the result, the most suitable air supply is $0.28 \mathrm{~m} / \mathrm{s}$ for for kitchen area $10 \mathrm{~m} \times 8 \mathrm{~m} \times 3 \mathrm{~m}$. As a conclusion, air ventilation in the commercial kitchen can be improved by choose a right air supply. However, another study need to be conduct in order to fulfill the comfort requirement in the kitchen space such as particular matter, other gasses, odor etc.

\section{Acknowledgements}

The authors would like to thank the Universiti Tun Hussein Onn Malaysia (UTHM) and Ministry of Higher Education (MOHE), Malaysia for supporting this research under the Fundamental Research Grant Scheme (FRGS) vote 1056 and Knowledge Transfer Program Grant (KTP) vote 1277.

\section{References}

1. S. P. Swierczyna R. and Fisher D., Effects of range top diversity, range accessories, and hood dimensions on commercial kitchen hood performance. ASHRAE 112(1), pp. 603-614, (2006).

2. C. B. Keil., H. Kassa, and F. Kenny, Kitchen hood performance in food service operations, J of Environment Health. 67(5), pp. 25-30, (2004).

3. R. Swiercyna, P. Sobiski, and D. Fisher, Effects of appliance diversity and position on commercial kitchen hood performance. American Society of Heating, Refrigerating and Air-Conditioning Engineers (ASHRAE) 112(12), pp. 591-602, (2006)

4. S. Saha, A. Guha, and S. Roy, Experimental and computational investigation of indoor air quality inside several community kitchens in a large campus. Building and Environment 52, pp. 177-190, (2012).

5. Improving commercial kitchen ventilation system: Optimizing make up air. ASHRAE, (2002)

6. Q. Chen, Comparison of different $\mathrm{k}-\varepsilon$ models for indoor air flow computations. Numer Heat Transfer, 28(B), pp.353-69, (1995)

7. Improving commercial kitchen ventilation system: Selecting and sizing hood performance. ASHRAE, (2002).

8. W. A. Hendrix, D. R. Henderson and H. Z. Jackson, Infiltration heat gains through cold storage room doorways. ASHRAE Transaction 95(2), pp. 1155-1168, (1989).

9. Z. Rabiah, Halton foodservice: Halton design guide for indoor air climate in commercial kitchens, (2007).

10.C. Lee and K. Lim, A numerical study on the characteristics of flow field, temperature and concentration distribution according to changing the shape of separation plate of kitchen hood system. Energy Building. 40(1), pp. 175-184, (2008). 